\title{
Bottled aqua incognita: microbiota assembly and dissolved organic matter diversity in natural mineral waters
}

\author{
Celine C. Lesaulnier ${ }^{1 \dagger}$, Craig W. Herbold ${ }^{1 \dagger}$, Claus Pelikan', David Berry', Cédric Gérard ${ }^{4}$, Xavier Le Coz ${ }^{4}$, \\ Sophie Gagnot ${ }^{4}$, Jutta Niggemann ${ }^{3}$, Thorsten Dittmar ${ }^{3}$, Gabriel A. Singer ${ }^{2+}$ and Alexander Loy ${ }^{1 *}$ (D)
}

\begin{abstract}
Background: Non-carbonated natural mineral waters contain microorganisms that regularly grow after bottling despite low concentrations of dissolved organic matter (DOM). Yet, the compositions of bottled water microbiota and organic substrates that fuel microbial activity, and how both change after bottling, are still largely unknown.

Results: We performed a multifaceted analysis of microbiota and DOM diversity in 12 natural mineral waters from six European countries. 16S rRNA gene-based analyses showed that less than 10 species-level operational taxonomic units (OTUs) dominated the bacterial communities in the water phase and associated with the bottle wall after a short phase of post-bottling growth. Members of the betaproteobacterial genera Curvibacter, Aquabacterium, and Polaromonas (Comamonadaceae) grew in most waters and represent ubiquitous, mesophilic, heterotrophic aerobes in bottled waters. Ultrahigh-resolution mass spectrometry of DOM in bottled waters and their corresponding source waters identified thousands of molecular formulae characteristic of mostly refractory, soil-derived DOM.

Conclusions: The bottle environment, including source water physicochemistry, selected for growth of a similar low-diversity microbiota across various bottled waters. Relative abundance changes of hundreds of multi-carbon molecules were related to growth of less than ten abundant OTUs. We thus speculate that individual bacteria cope with oligotrophic conditions by simultaneously consuming diverse DOM molecules.
\end{abstract}

Keywords: Bottled water, Microbial diversity, Dissolved organic matter, Fourier transform ion cyclotron resonance mass spectrometry, Aquabacterium, Curvibacter, Polaromonas

\section{Background}

Bottled water, including natural mineral water, is an increasingly popular source of drinking water around the world and represents a multi-billion-dollar industry. The European Union regulates the exploitation and marketing of natural mineral waters to protect their unique characteristics and original purity. The latest EU Directive 2009/54/EC defines natural mineral water as microbiologically wholesome water of underground origin that is protected from all risk of pollution and can be clearly

\footnotetext{
*Correspondence: loy@microbial-ecology.net

${ }^{\dagger}$ Equal contributors

${ }^{1}$ Department of Microbiology and Ecosystem Science, Division of Microbial Ecology, Research Network Chemistry meets Microbiology, University of Vienna, Althanstrasse 14, A-1090 Vienna, Austria

Full list of author information is available at the end of the article
}

distinguished from other types of drinking water, e.g., by its characteristic content of minerals and trace elements. Furthermore, disinfection or chemical treatment of natural mineral water is not permitted, yet it is routinely tested for its number of cultivable bacteria including several marker organisms (Escherichia coli and other coliforms, fecal streptococci, Pseudomonas aeruginosa, and sporulated sulfite-reducing anaerobes). The largely untreated nature of natural mineral waters allows that microorganisms from the source water aquifer and possibly the bottling plant (i.e., pipelines and storage tanks) act as inoculum for the bottle environment. Within a few days after bottling members of this "seed microbiota" begin to grow during storage of natural mineral waters at ambient 
temperature, with absolute cell counts reaching $10^{5}-10^{6}$ cells/mL [1-3].

Such microbial growth in non-carbonated bottled waters is a well-known fact, but the composition of the bottled water microbiota and its post-bottling dynamics have thus far been investigated by molecular techniques in only two natural mineral waters $[2,4]$. These and numerous isolation-dependent studies [5-8] have established that Alpha-, Beta-, and Gammaproteobacteria are the prevalent microorganisms in bottled water. Beyond this, many fundamental questions regarding the microbial ecology of bottled waters still remain poorly answered. How different is the microbiota in bottled waters from different sources? How does the bottled water microbiota assemble? Are there differences between the free-living community in the water phase (plankton microbiota) and the inner-bottle-surface-associated community (biofilm microbiota)?

A persistent question that has puzzled researchers for decades is what substrates in bottled water may fuel the observed sudden microbial growth [8]? Although autotrophic growth has been suggested [4], it is commonly assumed that bottled water microorganisms mainly generate energy and multiply through heterotrophic utilization of dissolved organic matter (DOM) available in the bottle environment [8]. Ground water, treated drinking water, and oligotrophic surface freshwaters generally have low DOM concentrations in the range of $0.5-5 \mathrm{mg}$ carbon/L. Microorganisms metabolize only a minor fraction $(0.01-0.1 \mathrm{mg}$ carbon/L) of this DOM pool while a larger refractory fraction remains untouched [9]. The susceptibility of DOM to microbial turnover depends on its origin and diagenetic history, which define chemical composition [10, 11], and its concentration, which defines the probability of microbial encounter for a specific chemical structure [12]. DOM analytics have been dramatically advanced by the advent of Fourier transform ion cyclotron resonance mass spectrometry (FT-ICR-MS) with ultra-high mass resolution allowing to accurately identify thousands of individual molecular formulae in a single environmental sample [13]. While FT-ICR-MS has provided fundamental insights into the molecular diversity of DOM and its turnover in various aquatic environments such as oceans [12-14], lakes [15], glaciers [11], and groundwater [16, 17], analogous information is not available for bottled drinking water.

Here, we simultaneously analyzed microbiota and DOM composition in 12 European non-carbonated natural mineral waters and their corresponding source waters by multiplexed sequencing of bacterial $16 \mathrm{~S}$ rRNA gene amplicons, FT-ICR-MS, and complementary analysis of microbiota and physicochemical parameters. Our approach included fine-scale temporal investigation of two representative bottled waters over 2 months of incubation and detailed comparative analysis of all 12 bottled waters 1 day after filling in polyethylene terephthalate (PET) bottles. We revealed corresponding patterns in DOM turnover and microbial community development after bottling and thereby provide novel insights into the molecular microbial and chemical ecology of this important drinking water source.

\section{Methods}

\section{Sampling and storage of natural mineral waters}

We analyzed non-carbonated natural mineral waters retrieved from 12 European bottling plants of well-derived mineral water in the years 2011 and 2012 (Additional file 1: Tables S1-S4). Samples from each plant included bottled water and corresponding well water; the latter was taken before its entry into the bottling plant from a sampling port located at the head of each source. Bottled water 6 receives water from two wells, $6 \mathrm{a}$ and $6 \mathrm{~b}$, while bottled waters $9 \mathrm{a}$ and $9 \mathrm{~b}$ receive water from the same well 9 . Bottled and well waters were filled in brand-specific $0.5 \mathrm{~L}$ and standard 1 L PET bottles, respectively. Water bottles were transported to the laboratory within $24 \mathrm{~h}$ and were subsequently stored in a dark, climate-controlled room (20$24{ }^{\circ} \mathrm{C}$ ) for sampling at regular time points after bottling. All bottled waters used in this study complied with the legal microbiological criteria (EU Directive 2009/54/EC).

\section{Recovery of plankton and biofilm biomass}

All waters were sampled in triplicate at each time point. Each replicate sample consisted of biomass from one or more separate bottles of water. Planktonic microorganisms were recovered on polycarbonate filters with a pore size of $0.22 \mu \mathrm{m}$ (GTTP04700; Millipore, Eschborn, Germany) using a stainless steel vacuum filtration unit equipped with three 500-mL filter funnels (Sartorius, Göttingen, Germany). Per replicate sample, 3 L (e.g., $6 \times 0.5 \mathrm{~L}$ bottles or $3 \times 1 \mathrm{~L}$ bottles) of water were filtered for nucleic acid extraction and 0.5 to $3 \mathrm{~L}$ for microscopy. Filters with cellular biomass were air dried, cut in half, and stored at $-80{ }^{\circ} \mathrm{C}$ for DNA extraction or fixed with para-formaldehyde and stored at $-20{ }^{\circ} \mathrm{C}$ for microscopy [2]. Biofilm samples were recovered from the inner linings of the same bottles that were used for harvesting planktonic biomass. Bottles were cut in half with a sterile scalpel blade and the entire inner surface of each bottle was swabbed with a sterile viscose collection swab (Deltalab, Carcassonne, France). The swab tips were then cut off and stored at $-80{ }^{\circ} \mathrm{C}$ prior to DNA extraction.

\section{Quantitative fluorescence microscopy}

FISH and DAPI-staining of microbial cells on polycarbonate filters was carried out as described previously [2]. 
Fluorescent cells were quantified by analyzing 20 pictures of randomly chosen fields of view per replicate sample with the image analysis program DAIME [18]. The following fluorescently labeled probes were applied for $\mathrm{FISH}$ using stringent hybridization conditions and, if applicable, together with their unlabeled competitor probes: EUB338 probe mix for Bacteria, ARCH915 for Archaea, ALF968 for Alphaproteobacteria, BET42a for Betaproteobacteria (GAM42a as competitor), AQUA827 for genus Aquabacterium, MEVE845 for the genus Methyloversatilis, and HGC69a for Actinobacteria [19]. Fluorescently labeled NONEUB probe was applied as negative control to all analyzed samples in order to assess unspecific-binding. Probe MEVE845 (S-G-MEVE-0845-a-A-21, 5' - TTA GCT GCG GTA CTC AAT GAG-3') and a corresponding competitor probe c1MEVE845 (5' - TTA GCT GCG TTA CTC AAT GAG-3') were newly designed based on the non-redundant ARB-SILVA database version 111Ref [20] using the probe tools of ARB [21], probeCheck [22], and RDP II [23]. Dissociation-curve analysis [18] with the perfectly matched type strain Methyloversatilis universalis showed that probe MEVE845 should be applied at 25\% formamide to ensure its specificity.

\section{DNA extraction}

Polycarbonate filters with planktonic biomass were first cut into smaller pieces with sterile scissors. Each sample (i.e., filter with planktonic biomass or swab tip with biofilm biomass) was transferred into an individual 2$\mathrm{ml}$ Lysis A matrix tube without the $1 / 4$ in. ceramic sphere (MP Biomedicals LLC, Solon, OH, USA). Cell lysis was initiated by adding $400 \mu \mathrm{l}$ of lysis buffer (10 mM Tris- $\mathrm{HCl}, 1 \mathrm{mM}$ EDTA, $100 \mathrm{mM} \mathrm{NaCl}, 0.5 \%$ SDS, $20 \mu$ g proteinase $\mathrm{K}, \mathrm{pH} 8$ ) and incubating at room temperature for $15 \mathrm{~min}$. Subsequently, $500 \mu \mathrm{l}$ of phenol-chloroform-isoamylalcohol (25:24:1, Carl Roth Karlsruhe, Germany) was added followed by vortexing for $2 \mathrm{~min}$ at maximum speed and centrifugation at $13,000 \mathrm{rpm}$ for $2 \mathrm{~min}$. The supernatant was recovered and further purified by a second round of phenolchloroform-isoamylalcohol treatment. DNA in the recovered supernatant was precipitated by adding 2.5 volumes of ice-cold 100\% ethanol, $1 \mu \mathrm{l} 3 \mathrm{M}$ sodium acetate ( $\mathrm{pH} 5$ ), and $1 \mu$ l glycogen and by incubating at $-20{ }^{\circ} \mathrm{C}$ for $2 \mathrm{~h}$. Precipitated DNA was recovered by centrifugation at $13,000 \mathrm{rpm}$ for $10 \mathrm{~min}$ and was washed with ice-cold $70 \%$ ethanol. Purified DNA was air dried, dissolved in $50 \mu \mathrm{l}$ sterile TE buffer $(10 \mathrm{mM}$ Tris- $\mathrm{HCl}, 1 \mathrm{mM}$ EDTA, $\mathrm{pH} 8)$ and stored at $-20{ }^{\circ} \mathrm{C}$.

\section{Quantification of nucleic acids}

DNA extracts and PCR products analyzed by agarose gel electrophoresis and quantified by using the Quant-iT PicoGreen dsDNA Assay Kit (Invitrogen Corporation,
Carlsbad, CA, USA). Samples and DNA standards were prepared as per manufacturer's instructions. Samples were placed in a black, flat bottom, 96-well plate (Greiner bioone, Frickenhausen, Germany) and were analyzed with a Microplate Reader (Tecan Infinite M200; Tecan Group Ltd., Männedorf, Switzerland).

\section{Multiplex amplicon pyrosequencing and sequence analysis}

Barcoded 16S rRNA gene amplicons for 454 pyrosequencing were prepared from planktonic and biofilm DNA using a previously published 2-step PCR procedure and primers (909F, 5' -ACTCAAAKGAATWGACGG-3' and 1492R, 5'-NTACCTTGTTACGACT-3') that amplify variable regions V6 to V9 of the $16 \mathrm{~S}$ rRNA gene of most bacteria [24]. To account for potential contamination [25], PCRs without addition of a DNA template or with DNA extracts from unused swap tips, swaps of empty bottles, and empty polycarbonate filters were performed during each PCR run. Most negative control PCRs did not yield a visible amplicon, except of six that showed a faint band in the agarose gel and were thus also sequenced. Pyrosequencing of barcoded amplicon pools was performed with Titanium reagents on a 454 genome sequencer FLX (Roche, Basel, Switzerland) by the Norwegian Sequencing Centre (Oslo, Norway) or by Eurofins Genomics (Ebersberg, Germany).

Raw 454 pyrosequencing flowgrams were denoised and checked for chimeras using AmpliconNoise [26] within the QIIME environment [27]. Denoised reads were subsequently clustered into OTUs at $97 \%$ identity, roughly corresponding to species-level OTUs [28], with UPARSE and an OTU table was generated with the associated uc2otu.py script [29]. Taxonomic classifications were assigned using the Ribosomal Database Project naive Bayesian classifier [30] using the Silva SSURef database v119 [31]. The OTU table and taxonomic classifications were imported into the R environment [32] for all further analysis. Contaminant OTUs were defined as OTUs that had higher relative abundance in negative controls than in samples (Additional file 1: Table S5). Contaminant OTUs and OTUs observed with fewer than three total counts across all samples were removed for all subsequent analysis. After sequence quality, contamination, and chimera filtering, a total of 567,310 reads from 215 individual samples, i.e., $2639 \pm 1650$ (mean $\pm \mathrm{SD}$ ) reads per sample, were retained (Additional file 1: Table S6).

Shannon and Simpson metrics were calculated using diversity() and estimateR() functions from the vegan package [33]. Goods coverage was calculated as 1-(number of singletons/number of reads) for each sample. Weighted UniFrac distance metrics were calculated using the UniFrac function from the Phyloseq package [34] and principal coordinate plots (PCoA) were generated using 
the $\mathrm{rda}()$ function in the vegan package. Specific hypothesis tests reported in the main text were conducted using cor.test(), wilcox.test() and/or t.test() from the statistics package in R. Multiple testing was accounted for using the Benjamini-Hochberg procedure with the p.adjust(method = "fdr") function. For all hypothesis tests and PCoA plots, the OTU table was re-sampled at 500 reads per sample and any sample with fewer than 500 reads was omitted. This procedure was repeated 100 times and mean $p$ values reported for hypothesis tests. Multiple re-samplings were visualized in PCoA plots by fitting sample coordinates together using the procrustes() function from the vegan package. Heatmaps show only OTUs that exceed $1 \%$ relative abundance in relevant samples, and associated dendrograms were calculated using the hclust(method = "average") function using distances calculated using dist.dna(pairwise.deletion = TRUE) on an alignment of reads constructed with mafft -linsi [35].

"Growing OTUs" were determined by correlating estimated OTU cell numbers to the number of days after bottling in a resampling scheme. First, total cell numbers for a sample were estimated using the rnorm() function with the measured mean and standard deviation as the input distribution. Then, samples were resampled as previous but used to calculate a resampled relative abundance. Resampled relative abundance was subsequently multiplied by estimated DAPI-cell count to estimate the number of cells from each OTU in a resampled community. During each resampling iteration, Pearson correlations and associated $p$ values were calculated between $\log ($ cell count +1$)$ and $\log$ (day after bottling). The resampling procedure was repeated 100 times, and the median $p$ values for each OTU was adjusted using the BenjaminiHochberg procedure with the p.adjust(method = "fdr") function. Growing OTUs were defined as those OTUs with a significant adjusted median $p$ value $(<0.05)$ for a positive correlation of estimated cell number with time.

Three sets of "core OTUs" were defined as those seen in (1) a majority of well waters, (2) a majority of early bottled waters (1 day after bottling) or (3) a majority of late bottled waters ( $\geq 14$ days after bottling). In each case "majority" is in regard to the number of distinct water types $(n=12)$, not samples. A final set of ubiquitous OTUs was defined as those OTUs present in all three core OTU definitions.

\section{Clone library preparation and Sanger sequencing}

Almost full-length bacterial 16S rRNA genes were amplified with primers 616V (5'-AGAGTTTGATYMTG GCTC-3'; [36]) and 1492R (5'-NTACCTTGTTACG ACT-3'; [24]). Individual PCRs were carried out using planktonic DNA samples from water 1 (3 and 28 days after bottling) and water 2 (6 and 28 days after bottling) obtained in the year 2011, the Taq DNA polymerase kit (Fermentas Inc., Hanover, MD, USA), and nucleotide$\operatorname{mix}(2 \mathrm{mM} / \mathrm{dNTP})$ (Fermentas Inc., Hanover, MD, USA) as per manufacturer's instructions and at an annealing temperature of $51{ }^{\circ} \mathrm{C}$ and with 25 cycles. PCR amplicons were cloned using the pCR2.1 TOPO TA cloning kit (Invitrogen Corporation, Carlsbad, CA, USA) as per manufacturer's instructions. Plasmid DNA from each clone was purified using the QuickLyse Miniprep Kit (Qiagen, Venlo, The Netherlands), and inserts were sequenced by Microsynth (Balgach, Switzerland). The recovered sequences were manually proofread using the sequence and chromatogram software FinchTV V1_4_0 (Geospiza/Perkin Elmer, Seattle, WA, USA).

\section{Phylogenetic analyses}

Near full-length 16S rRNA gene sequences and representative reads of 454-derived OTUs that were identified as core and/or growing OTUs were used for phylogenetic reconstruction. Appropriate reference sequences were identified using a combination of blastn, the Ribosomal Database Project sequence match tool and the ARB software package with the Living Tree Project database release 108 [21, 37]. In cases in which the 454-derived OTU sequence completely matched a full-length 16S rRNA clone or reference sequence, only the full-length sequence was used for treeing. The final set of sequences was aligned using SINA [38], and the phylogeny was calculated using both RAxML [39] and Phylobayes 3 [40]. The RAxML tree was calculated using the GTRGAMMA model with 1000 rapid bootstraps. The Phylobayes tree was calculated using the GTR model with 4 gamma-distributed rate categories and 5 independent chains of 40,000 generations. The first 10,000 generations of each chain were discarded as burn-in for posterior probability calculations.

\section{Physicochemical analyses}

Prior to biomass recovery, the oxygen concentration in the water bottles was measured using a needle-type oxygen microsensor and a Microx TX3 Micro fiber optic oxygen transmitter (PreSens Precision Sensing, Regensburg, Germany). Calibration and measurements were performed as per manufacturer's instructions. PET bottles were pre-pierced with a sterile needle followed by immediate injection of the microsensor optode into the water for oxygen measurements. Additional water parameters were measured by the Nestle Quality Assurance Center using potentiometry (e.g., $\mathrm{pH}$, conductivity, and alkalimetry), flow injection analysis (e.g., nitrate, nitrite, ammonium, and orthophosphate), inductively coupled plasma mass spectrometry (e.g., calcium, magnesium, sodium, potassium, sulfate, silica, iron, and manganese). 


\section{Assimilable organic carbon}

The amount of organic carbon that was assimilated by the growing microbial community was inferred based on total cell counts at the beginning and end of microbial growth as previously described [41].

\section{Dissolved organic matter extraction}

DOM from all samples was extracted from respective volumes $(0.5-5 \mathrm{~L})$ corresponding to approximately $0.25-$ $1 \mathrm{mg}$ total dissolved organic carbon. Water was filtered directly from the original, brand-specific PET bottles $(0.5 \mathrm{~L})$ or standard PET sampling bottles (well water) through a double layer of pre-combusted $\left(450{ }^{\circ} \mathrm{C}, 4 \mathrm{~h}\right)$ glass fiber filters $(0.7-\mu \mathrm{m}$ pore size, Whatman $\mathrm{GF} / \mathrm{F})$ into acid-washed pre-combusted glassware. All bottled water and well water samples were analyzed in triplicate per time point; for each replicate water from independent original product or sampling bottles $(0.5-1 \mathrm{~L})$ was pooled as necessary to reach adequate volumes. In parallel to each set of samples, we filtered equal volumes of Milli-Q water as blank DOM controls. Filtered water was then used for extraction of DOM [42] on a solid phase (Agilent Bond Elut PPL $3 \mathrm{ml} 100 \mathrm{mg}$ cartridges, VWR, Arlington Heights, USA) after acidification to $\mathrm{pH} 2$ (Suprapur-grade $\mathrm{HCl}$, Carl Roth, Mannheim, Germany). DOM was eluted from cartridges with LC-MS-grade methanol (Sigma Aldrich, St Louis, USA) and was stored in pre-combusted 4-mL amber glass vials at $-20{ }^{\circ} \mathrm{C}$ pending FT-ICR-MS. We quantified dissolved organic carbon in the original filtered water by wet-chemical oxidation (Sievers 900 TOC Analyzer operated with an inorganic carbon removal unit). We determined a method detection limit of the Sievers 900 according to US EPA guidelines of approximately $6 \mu \mathrm{g} \mathrm{C} \mathrm{L} \mathrm{L}^{-1}$.

\section{FT-ICR-MS and MS-data preprocessing}

Mass spectrometry of DOM extracts (adjusted to $20 \mathrm{ppm}$ carbon in 1:1 methanol/ultrapure water) was done on a 15 Tesla Solarix FT-ICR-MS (Bruker Daltonics, Bremen, Germany) in electrospray ionization (ESI) negative mode (500 accumulated scans, $2 \mathrm{~s}$ ion accumulation time) searching for masses from 153 to $2000 \mathrm{Da}$. No peaks were detected for masses $>1000 \mathrm{Da}$. Following internal calibration, peaks with $\mathrm{S} / N>3$ were exported from Bruker-Data Analysis software for further data analysis using in-house code in R [32] (Additional file 1: Table S9). A first assignment of molecular formulae to peaks was done assuming single-charged deprotonated molecular ions and $\mathrm{Cl}$-adducts for a maximum elemental combination of $\mathrm{C}_{100} \mathrm{H}_{250} \mathrm{O}_{80} \mathrm{~N}_{4} \mathrm{P}_{2} \mathrm{~S}_{2}$, with a mass tolerance of $0.6 \mathrm{ppm}$, and using the following restrictions: agreement with the nitrogen rule, positive integer double bond equivalent for uncharged molecule, minimum $\mathrm{C}_{1} \mathrm{H}_{1} \mathrm{O}_{1}$, $\mathrm{P}<(\mathrm{O}+1), \mathrm{S}<(\mathrm{O}+1), \mathrm{H}: \mathrm{C}$ within $[0.3,2.5], \mathrm{O}: \mathrm{C}$ and
$\mathrm{N}: \mathrm{C}$ within $[0,1], \mathrm{H} \leq 2 \mathrm{C}+2+\mathrm{N}$, at least $1 \mathrm{O}$ for each $\mathrm{P}$ or $\mathrm{S}$, and no heteroelement $(\mathrm{N}, \mathrm{S}, \mathrm{P})$ co-occurrence. We then checked for isotope confirmation of all potentially valid formulae using generated isotope intensity patterns (up to 10 daughter peaks considering isotopes of all elements except $\mathrm{P}$ ) and based on adequate mass shift(s) (tolerance $0.6 \mathrm{ppm}$ ) and adequate intensity ratio(s) $( \pm 40 \%)$ of isotopic daughter peaks to the monoisotopic, parent peak [43]. For formulae assigned to the molecular groups of condensed polyaromatics, saturated fatty acids and carbohydrates, and involving heteroatoms (N, S, P) (see below), more stringent limits were set for isotope confirmation (halved tolerance and halved maximum deviation from the expected peak ratio). A single daughter isotope peak sufficed for confirmation of a suggested sum formula, two daughter peaks were minimum for sum formulae with $\mathrm{Cl}$, which has abundant secondary isotopes and produces prominent daughter peaks besides those produced by exchange of ${ }^{12} \mathrm{C}$ by ${ }^{13} \mathrm{C}$. In case of multiple assignments to the same peak, we gave preference to (i) extremely abundant molecules commonly found in environmental samples (CHON, $\left.\mathrm{CHON}_{2}, \mathrm{CHOS}\right)$, (ii) formulae with better isotope confirmation (more daughter peaks and isotope confirmation across a greater number of samples), and (iii) formulae involved in longer homologous series based on $\mathrm{CH}_{2}$ (aliphatic elongation) and $\mathrm{CO}_{2}$ (acid-based elongation). Intensities of formulae found in deprotonated charged state and as a $\mathrm{Cl}$-adduct were summed. Finally, we aligned detected masses across samples based on assigned formulae, keeping only formulae that achieved stable isotope confirmation in at least one sample [11]. One hundred and twenty-six formulae assigned to mass peaks with $\mathrm{S}: N>5$ found in any of a total of 20 blank samples were considered to be contaminants and deleted from the dataset.

\section{DOM data analysis}

FT-ICR-MS data is graphically presented in van Krevelen plots, which show identified sum formulae in a space defined by $\mathrm{O}: \mathrm{C}$ (oxygen richness) and $\mathrm{H}: \mathrm{C}$ (saturation) ratios; plotting order was random to avoid bias created by systematic overplotting as is common in van Krevelen plots showing thousands of compounds.

Before statistical analysis, we further filtered the dataset based on a "replicate filter," i.e., any singlet molecular formula determined for a set of replicates was deleted [44]. As replicate sample sets, we considered all samples from the same source and incubation time. This filter was not applied to the single replicate of Well 8. The final dataset consisted of 4055 sum formulae. To condense these information, we grouped molecular formulae into 12 non-overlapping molecular groups based on elemental composition and derived 
structural information such as double bond equivalents (DBE) and a computed aromaticity index [45]; the most prevalent categories are reported and defined in Additional file 1: Table S8. While this categorization is to some degree arbitrary, it allows an overview of the molecular data. As descriptors of molecular diversity, we report the total number of identified sum formulae (richness), the Shannon-Wiener index and evenness. To investigate compositional changes of DOM over time or due to geographical variation among wells, we used principal component analysis (PCA) based on centered log-transformed relative intensity data (separately for the "time-course experiment" datasets of waters 1 and 2, and for the "diversity study" dataset). Time-course data was also used in redundancy analysis [46] with incubation time as the single constraint to identify significance of temporal changes of DOM composition. Principal components, i.e., gradients of major compositional variation of DOM, were (i) plotted against other variables (e.g., incubation time) and were (ii) correlated (Spearman) with relative intensities of individual molecular formulae for color-coding molecules in the van Krevelen space. For the time series datasets, we also opposed sets of molecular formulae with very low/high correlation coefficients $(<20$ and $>80 \%$ quantiles $)$ with respect to their location in van Krevelen space, dominance of molecular groups and molecule mass. These two formula sets serve to describe two pools of compounds likely decreasing and increasing during incubation; it is impossible to unequivocally identify decrease or increase of a compound from relative intensity data. All data analysis was carried out in $\mathrm{R}$ version 3.2.1 [32] using the packages vegan [33] and MASS [47].

\section{Results}

Bacterial community and dissolved organic matter composition during microbial growth in two representative bottled waters

We analyzed microbial growth, physicochemical properties, bacterial community composition, and molecular DOM composition in two non-carbonated bottled waters, water 1 from France and water 2 from Poland, during 56 days of storage after filling in brand-specific PET bottles at the bottling plant. The two waters were selected to represent the range of DOM concentrations (water $1<0.06 \mathrm{mg}$ carbon/L, water $21.0-1.2 \mathrm{mg}$ carbon/L) that are typical for bottled waters at the time of bottling (Table 1, Additional file 1: Tables S1 to 4). This time-course experiment was performed twice in two consecutive years $(2011,2012)$, but in-depth analysis of DOM was restricted to 2012 when we also conducted an analysis of the well waters sampled into identical standard PET bottles at the bottling plant. Generally, small temporal variations in generic physicochemical parameters were observed in both waters during storage (Table 1, Additional file 1: Tables S1 and S2). The two waters differed in mineral content and with respect to concentrations of dissolved oxygen, the latter is likely because of the differences in initial pressure under which these waters were bottled (Table 1, Fig. 1). Microorganisms were not limited by oxygen availability in either water as oxygen concentrations were never below $6.9 \mathrm{mg} / \mathrm{L}$ (Fig. 1) [48]. Microorganisms multiplied in both waters as observed for other noncarbonated bottled waters [2]. Within a week, total cell counts increased several fold to $\geq 10^{5}$ cells $/ \mathrm{mL}$ and remained at this concentration until the end of the experiment. While water 2 contained $>20$ times more DOM than water 1 (Table 1 ), only about 2-4 times more organic carbon was assimilated by the microbiota in water $2(18.2 \mu \mathrm{g} / \mathrm{L}$ in year $2011,40.1 \mu \mathrm{g} / \mathrm{L}$ in year 2012) than water $1(10.4 \mu \mathrm{g} / \mathrm{L}$ in year $2011,20.9 \mu \mathrm{g} / \mathrm{L}$ in year 2012). This indicated that only a small fraction of total DOM was immediately available for microbial growth, as has been shown for other types of oligotrophic drinking waters [9].

Initial screening of the two bottled waters during and after microbial growth by fluorescence in situ hybridization (FISH) with domain-specific probes showed a prevalence of bacteria (Additional file 2: Figure S1), which corroborated previous studies that archaea and eukaryotic microorganisms are absent or low in abundance in bottled groundwater [2, 4, 49]. We thus focused all subsequent microbial analyses on the bacterial community. Temporal variations in planktonic and biofilm community structure after bottling were revealed by multiplex pyrosequencing of bacterial 16S rRNA gene amplicons. The retrieved, quality-filtered sequences in the time-course experiment dataset consisted of 672 specieslevel operational taxonomic units (OTUs), with 127 having $\geq 1 \%$ relative abundance in at least one sample. Seventy and 115 of these abundant OTUs were detected in waters 1 and 2, respectively, of which 58 OTUs were present in both waters and 10 grew over the time-course experiment (Additional file 1: Tables S6 and S7).

Bacterial diversity within each sample (alpha-diversity, e.g., Chao1) was overall higher in water 2 than that in water 1 (Additional file 1: Table S6, median resampled $p<1 \times 10^{-9}$, two-sample $t$ test for all alpha-diversity metrics). Onset of planktonic microbial growth in both waters was accompanied by a considerable decrease in both alpha-diversity (median resampled $p<0.015$, for correlation of any alpha-diversity measure in either water against $\log ($ days after bottling)) and pair-wise diversities between all samples at a given time point (betadiversity: median resampled $p<0.024$, for correlation of 


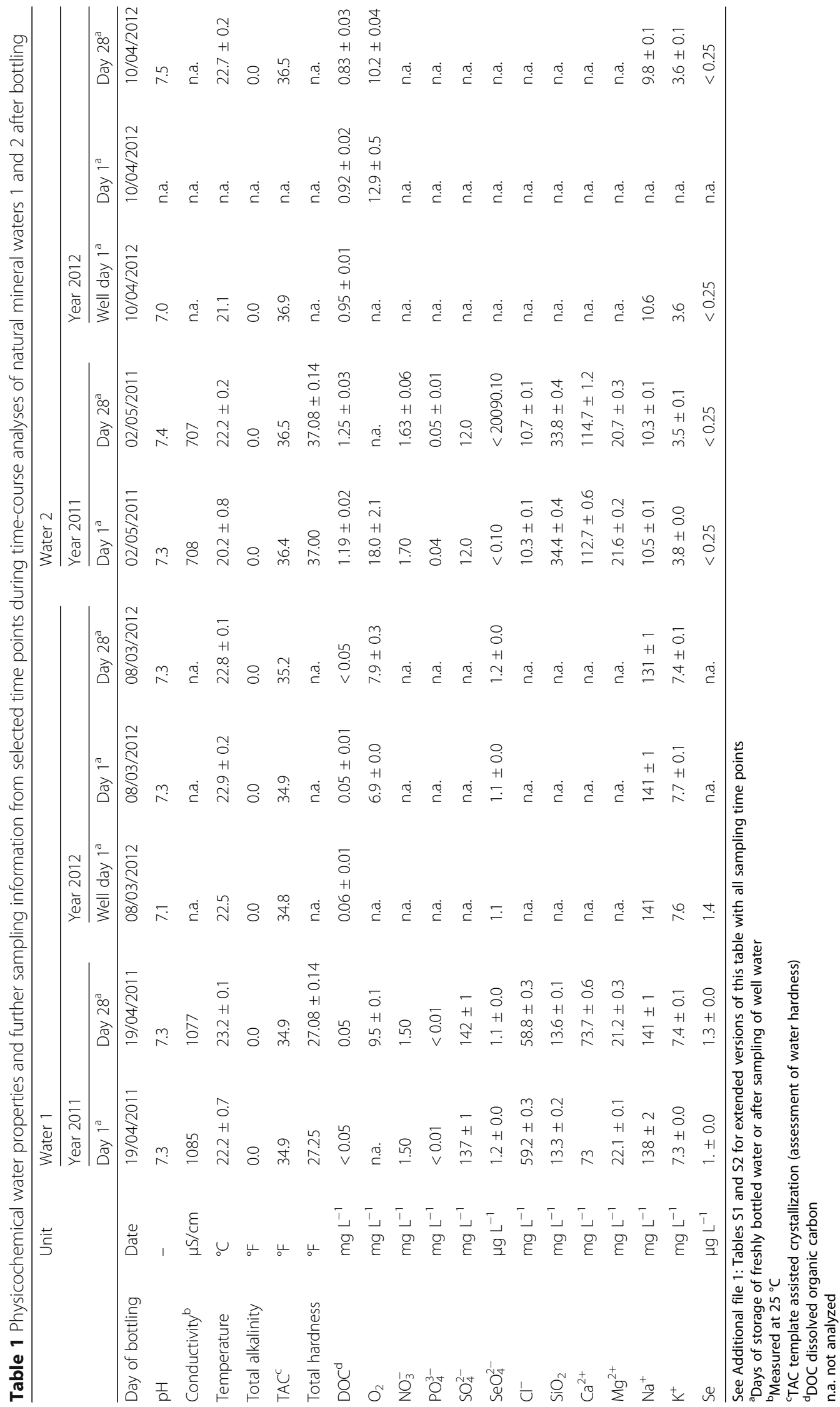




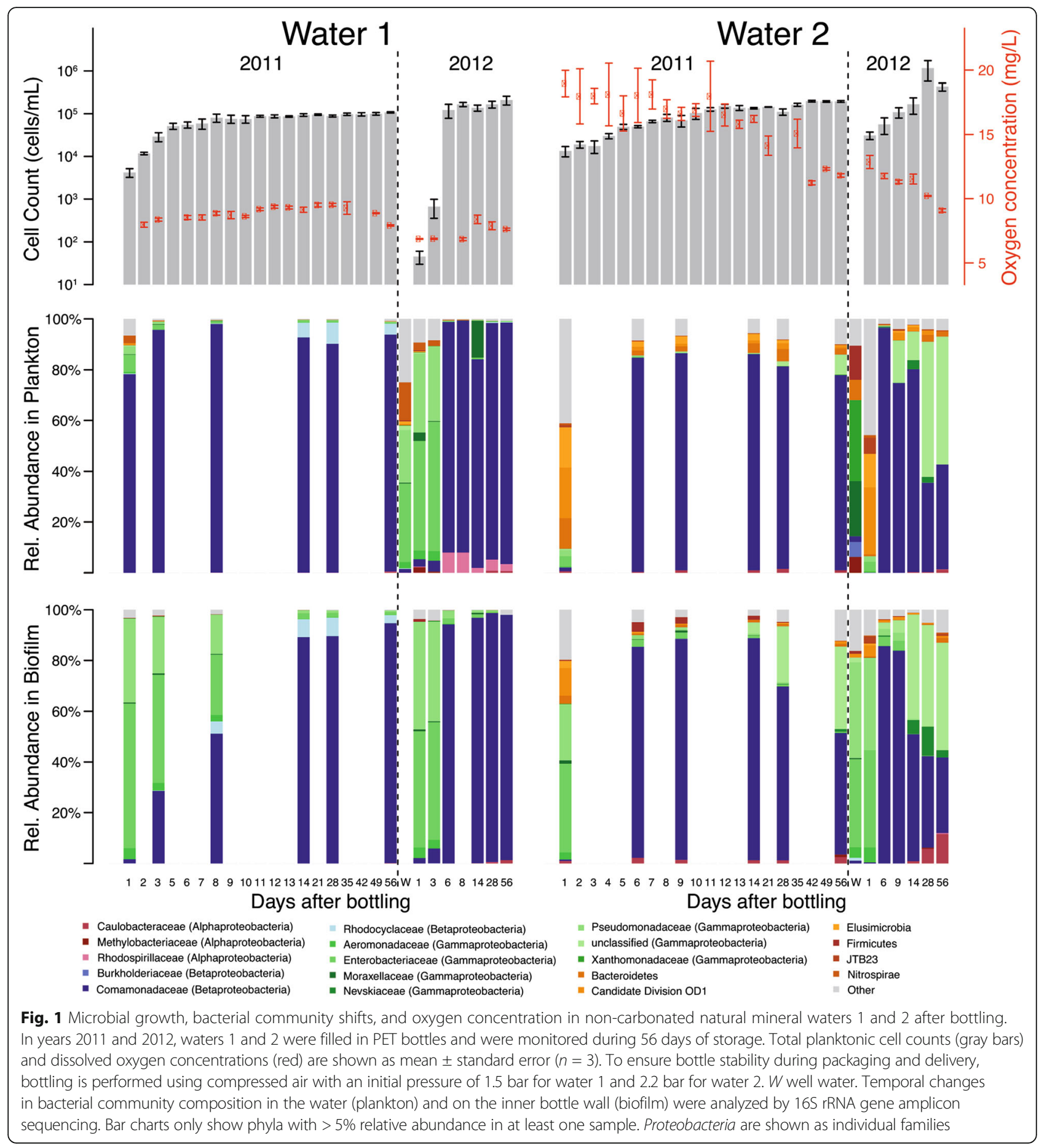

unifrac distance against $\log$ (days after bottling) for each water). Planktonic and biofilm communities within and between the two waters were clearly different early after bottling but converged into very similar communities within 9 days of storage (Figs. 1 and 2). After day 7, when most of the increase in total cell counts had occurred, only 1-6 (median 2) and 4-15 (median 6.5) OTUs made up $\geq 90 \%$ of the relative $16 \mathrm{~S}$ rRNA gene read count throughout the remaining incubation time in waters 1 and 2, respectively.

In water 1, 16S rRNA genes from Gammaproteobacteria (Enterobacteriaceae, Pseudomondaceae) generally dominated in low-biomass well water and bottled water samples from early time points (Fig. 1). However, members of the class Betaproteobacteria (Comamonadaceae) contributed most strongly to microbial growth and continued to 

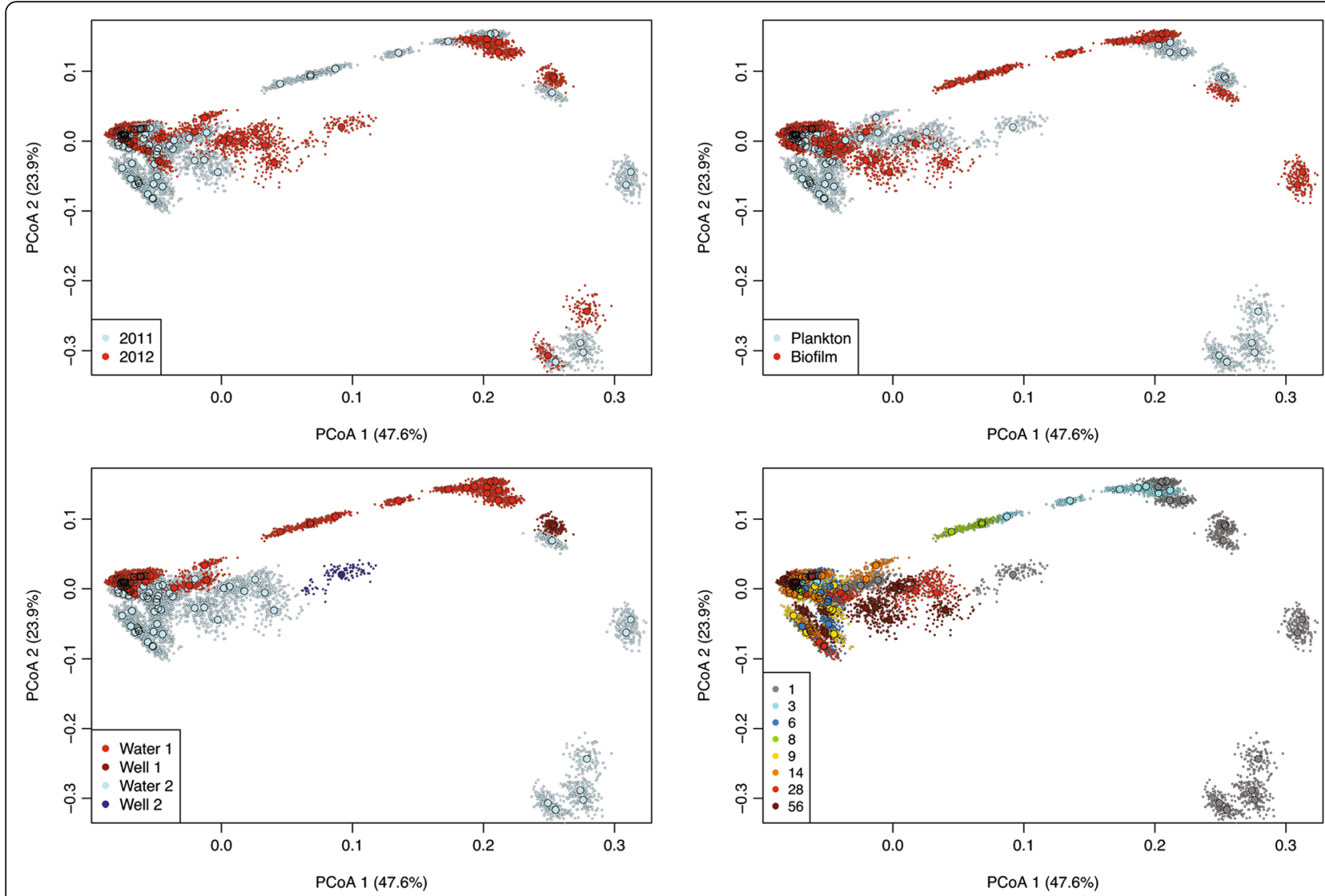

Fig. 2 Microbiota beta-diversity in natural mineral waters 1 and 2 after bottling. PCoA analysis based on weighted UniFrac distances calculated from bacterial $16 \mathrm{~S}$ rRNA gene amplicon data. Each larger circle indicates the microbiota of an individual replicate water sample. In silico dataset re-sampling is visualized in PCoA plots as smaller circles. Each panel shows the same PCoA plot with individual coloring according to the year of sampling (year 2011 vs year 2012), type of microbiota (plankton vs biofilm), type of water (well water vs bottled water; water 1 vs water 2), and days after bottling (between 1 and 56 days)

dominate the planktonic and biofilm communities throughout the incubations. Early after bottling, water 2 had higher phylum/class/family-level diversities than water 1 , with considerable representation of $16 \mathrm{~S}$ rRNA genes from the Alpha-, and Gammaproteobacteria, Bacteroidetes, Elusimicrobia, and the candidate phyla radiation lineage OD1 (Parcubacteria) (Fig. 1) [50]. Microbial growth in water 2 was also mainly due to Betaproteobacteria (Comamonadaceae).

Regarding species-level OTU composition immediately after bottling, the gammaproteobacterial OTUs 3, 4, and 21 were most abundant in $16 \mathrm{~S}$ rRNA sequence libraries of both waters (Additional file 2: Figure S2). Subsequent microbial growth in both waters and in both years was attributed to OTUs 1 (Curvibacter, Comamonadaceae) and 2 (Aquabacterium, Comamonadaceae) (Additional file 2: Figure S3, Additional file 1: Table S7). In addition to these two ubiquitous OTUs, there were further OTUs that grew inconsistently, usually only in a single year for a particular water source. For example, OTU 13 (Methyloversatilis, Rhodocyclaceae) grew only in water 1 from 2011. Instead,
OTUs 25 (unclassified Xanthomonadales), 68 (unclassified Xanthobacteraceae), and 1408 (unclassified Comamonadaceae) contributed to bacterial growth in water 2 in 2011. Different OTUs contributed to growth in water 2 samples from 2012, namely, OTU 9 (unclassified Xanthomonadales) and OTU 993 (Polaromonas, Comamonadaceae). For phylogenetic analysis, we recovered near fulllength bacterial 16S rRNA gene sequences from year 2011 samples of both waters at later post-bottling time points (Additional file 2: Figure S3). Several OTUs had $100 \%$ identity to near full-length $16 \mathrm{~S}$ rRNA sequences from this and other studies. For example, sequences of OTUs 1 and 2 perfectly matched Curvibacter fontanus AQ12 (AB120966) [51] and Aquabacterium parvum B6 (AF035052) [52], respectively. FISH experiments confirmed the dominance of Betaproteobacteria and the high relative abundances of specific genera during and after microbial growth in the respective water samples (Additional file 2: Figure S1).

FT-ICR-MS analysis of water samples taken during the time-course experiment in 2012 revealed high DOM 
complexity and similar temporal dynamics despite considerable differences in total DOM concentrations and composition between the two waters (Additional file 2) (Figs. 3 and 4, Additional file 1: Table S3 and S4). We identified a total of 3152 and 3177 different molecular formulae across the time-course experiment of waters 1 and 2, respectively. Each water sample contained on average more than 2500 different molecular formulae (water 1, $2496 \pm 135$; water 2, $2825 \pm 115$ ). Molecular formulae indicative of condensed aromatic structures, of likely pyrogenic origin, were rare in water 1 and not detected in water 2 (Additional file 2: Figure S4, Additional file 1: Table S8). Most molecular formulae were representative for unsaturated aliphatic, polyphenolic, and highly unsaturated phenolic compounds. The latter comprised on average 97 and $95 \%$ of the total signal intensity of each mass spectrum of waters 1 and 2, respectively. In contrast, molecular formulae that are consistent with peptide, fatty acid, and carbohydrate structures were low in relative abundance $(<0.05 \%$ of overall intensity, $<0.3 \%$ of formulae count). The dominance of potentially refractory molecules suggested that most DOM in both waters may not be readily degradable by microorganisms on the timescales investigated in this study. Nevertheless, we revealed significant compositional changes in DOM during storage (water 1 , canonical $R=0.94, p<0.001$; water 2 ,

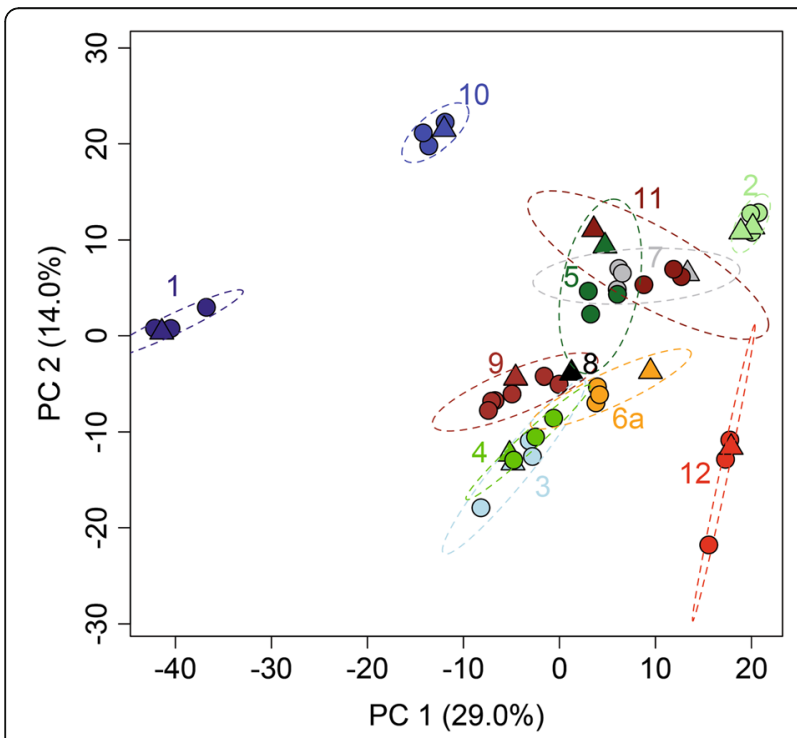

Fig. 3 Variation of DOM composition across all well and bottled waters 1 day after filling. PCA based on log-transformed relative signal intensities (FT-ICR-MS) of identified molecular formulae shows strong compositional contrasts between water types (identical color); the well water samples (triangles) largely cluster with the corresponding bottled water (circles) with some bottle-specific variation. Numbers refer to water types. No data was available for well $6 \mathrm{~b}$. Well 8 was described by a single sample. Ellipses correspond to $99 \%$ confidence limits of PCA-scores canonical $R=0.96, p<0.01$ ) that affected a similar group of compounds in both waters (Fig. 4, Additional file 2: Figure S5). These incubation time-associated shifts in DOM composition were also reflected in diversity patterns. Diversity and richness of DOM increased, evenness decreased during storage for water 1 , yet no significant trends were identified for water 2 (Additional file 2: Figure S6). The strongest changes in molecular DOM composition occurred at the onset of and during microbial growth, which suggests that these shifts were mainly driven by the growing microorganisms (Fig. 4).

Core microbiota and diversity of dissolved organic matter in various European bottled waters and corresponding well waters

We further analyzed physicochemical properties (e.g., $\mathrm{pH}$ and oxygen), bacterial community composition, and molecular DOM composition in 12 natural mineral waters from Belgium, France, Poland, Switzerland, Spain, and the UK (referred to as the diversity study). As aforementioned, higher oxygen concentrations in freshly bottled water $(6.3-18.0 \mathrm{mg} / \mathrm{L})$ than in well waters $(4.6-5.7 \mathrm{mg} / \mathrm{L})$ (Table 1, Additional file 1: Tables S3 and S4) are likely due to pressure filling. Changes in the planktonic and biofilm bacterial communities between days 1 and 28 of the various bottled water and well water samples were analogous to the time-course experiment. The taxonomic diversity and, based on rarified and resampled datasets, the mean number of observed (44 vs 17), estimated (Chao1: 64 vs 24 ), and dominant (>1\%: 11 vs 5 ) OTUs were higher at day 1 than at day 28 (Additional file 2: Figure S7, Additional file 1: Table S6). Beta-diversity was higher between day 1 samples than between day 28 samples (median resampled $p<0.001$, two-sample $t$ test and Mann-Whitney test), which indicates that growth of few, phylogenetically similar bacteria was driving converging microbiota compositions (Additional file 2: Figure S8). Only samples from water/well 6 contained bacterial communities that differed extensively from other samples at day 28. In general, only between 1 and 15 OTUs (mean 4) collectively contributed $>90 \%$ of the $16 \mathrm{~S}$ rRNA gene abundance in each bottled water at day 28 post bottling. At this time point, dominant OTUs in plankton and/or biofilm communities were members of the Betaproteobacteria (mostly Comamonadaceae, but also Rhodocyclaceae, Oxalobacteraceae, and Methylophilaceae), Alphaproteobacteria (Caulobacteraceae), Gammaproteobacteria (Nevskiaceae, unclassified family), and Spirochaetes (Leptospiraceae) (Additional file 2: Figures S7 and S9).

Using the combined 16S rRNA sequence dataset from the time-course experiment and the diversity study (215 samples), we determined the core microbiota in three categories of bottled water samples: (1) "well water" samples, 

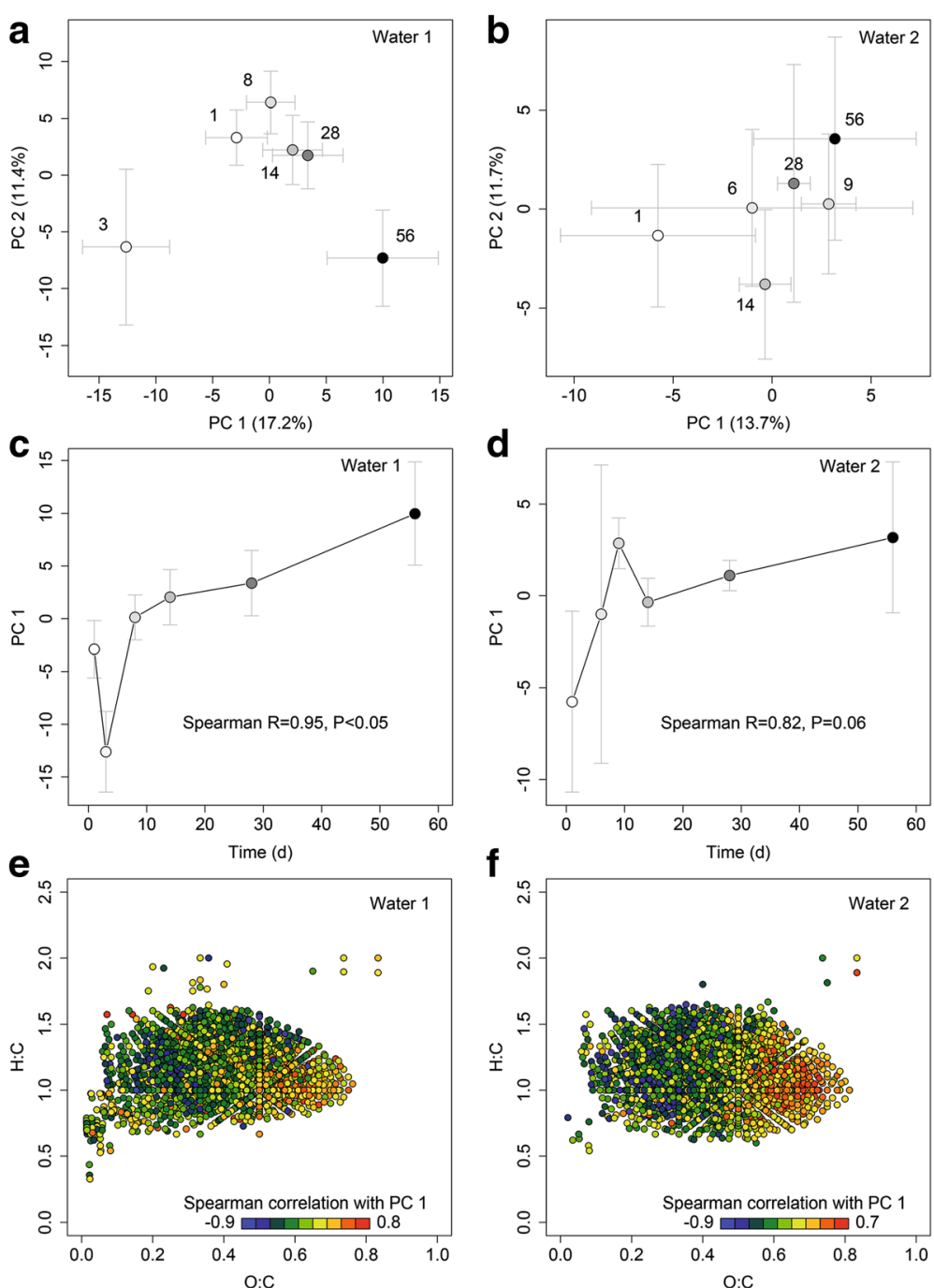

Fig. 4 Temporal changes of dissolved organic matter composition in natural mineral waters 1 and 2 after bottling. In year 2012, waters 1 and 2 were filled in PET bottles and were monitored during 56 days of storage. a, b PCA based on log-transformed relative signal intensities (FT-ICR-MS) of identified molecular formulae; crosses are mean ( \pm SD) scores of 3 replicates, numbers and coloring refer to incubation time (days after bottling). c, $\mathbf{d}$ Dominant compositional change of DOM (as captured by the PC 1) over incubation time; mean ( \pm SD) scores of 3 replicates. e, $\mathbf{f}$ van Krevelen plots of sum formulae identified by FT-ICR-MS in waters 1 and 2. Each dot represents one sum formula and its location informs about oxygen richness (O:C) and saturation ( $\mathrm{H}: \mathrm{C})$. Dot color shows Spearman correlation coefficients of relative signal intensity with the PC 1; red (positive correlation) and blue (negative correlation) indicate formulae likely increasing and decreasing over incubation time, respectively. Only sum formulae detected at least four times are shown to avoid artificially inflated correlations

(2) "early bottled water" samples from day 1 after bottling that contain the seed microbiota, and (3) "late bottled water" samples from $>14$ days after bottling that contain the mature microbiota after growth has occurred. We also identified the OTUs that were shared between the core microbiota in these three categories as "ubiquitous" OTUs. Good's coverages of individual $16 \mathrm{~S}$ rRNA sequence libraries ranged from 86 to $100 \%$ (mean 99\%) (Additional file 1: Table S6), indicating that the majority of OTUs in each sample was detected. We here define the core microbiota, by considering OTU abundance and habitat occupancy [53], as the sum of OTUs that are each present at a relative abundance of $\geq 0.5 \%$ per sample and in $\geq 50 \%$ of all water brands ( 12 in total) per category.

The sum of all non-redundant OTUs across all samples was 1295 , of which only 12 OTUs were identified as core microbiota (Fig. 5). These 12 core OTUs belonged to either Gammaproteobacteria or Betaproteobacteria (Fig. 5, Additional file 2: Figure S3). OTU 3 (Pseudomonadaceae), OTU 181 (Oxalobacteriaceae), and OTUs 1 and 2 (Comamonadaceae) were ubiquitous across all three core categories considered. The well 
a

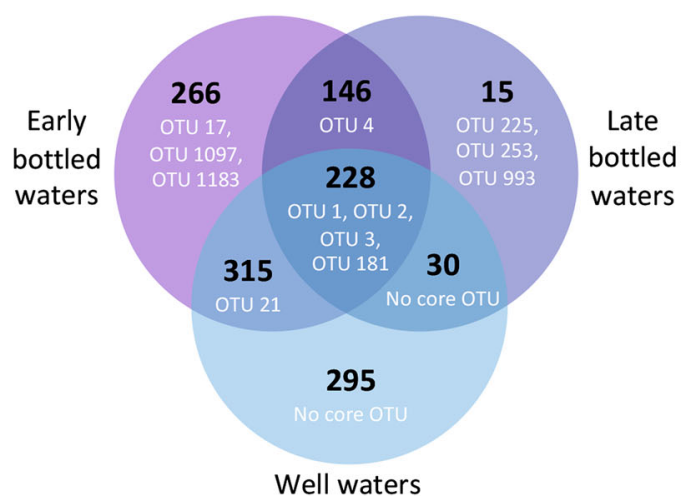

b
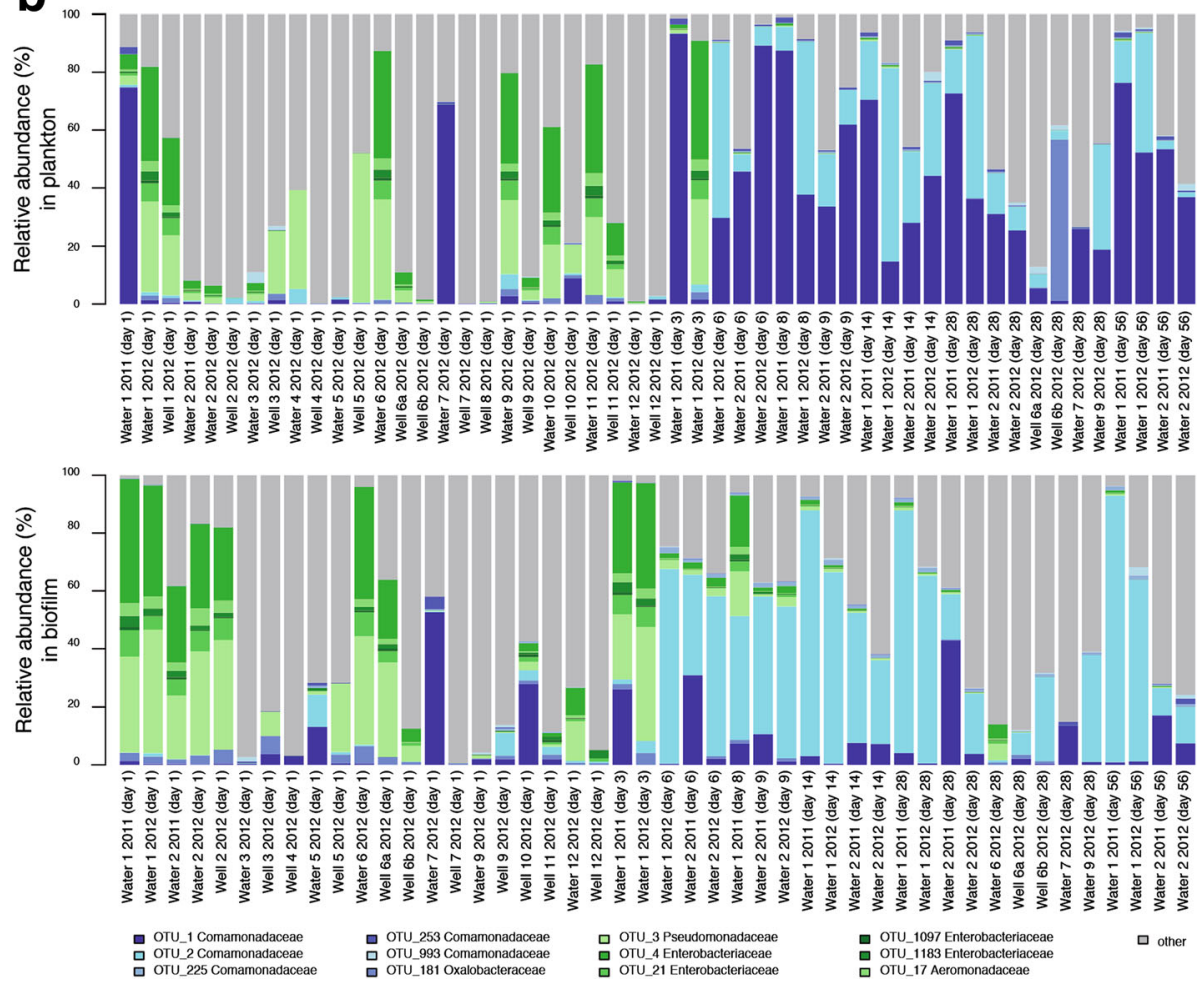

Fig. 5 The core microbiota of bottled water. a Venn diagram showing core OTUs (in white, with their individual names) and the total number of OTUs (in black) in well waters or bottled waters sampled 1 day ("early") and > 14 days ("late") after filling in PET bottles and how these are shared between these categories. $\mathbf{b}$ Mean relative abundances of the 12 core OTUs in all analyzed plankton and biofilm samples from different days after bottling. For example, OTU 1 was more abundant in plankton than in biofilm ( $p=4.37$-08) and OTU 2 was more abundant in biofilm than in plankton ( $p=0.006867$ ) (based on one-sided Wilcoxon rank sum test). Furthermore, OTU 1 was more abundant in plankton $(p=0.008156)$ and less abundant in biofilm ( $p=4.423 \mathrm{e}-05)$ than OTU 2 (based on paired one-sided Wilcoxon signed-rank test)

water core consisted of the four ubiquitous OTUs and OTU 21 (Enterobacteriaceae). The shift from well water to early bottled water was marked by the addition of four additional members (OTUs 4, 17, 1097, and 1183) of the Gammaproteobacteria, which were generally more abundant at these early time points (Additional file 2: Figure S7). The subsequent change from early to late bottled water was characterized by the replacement of four gammaproteobacterial OTUs (OTUs 17, 21, 1097, and 1183) by three Comamonadaceae (OTUs 225, 253, 993).
At these later time points, the Comamonadaceae also dominated the mature microbiota in most waters (Fig. 5). Hence, microbial succession during storage of bottled waters was uniquely characterized by a shift from a gammaproteobacterial to a betaproteobacterial core microbiota.

Early (day 1) bottled and well water samples were analyzed by FT-ICR-MS to characterize and compare their DOM composition and molecular diversity. Collectively, 3813 different molecular formulae were identified across all samples (Additional file 2: Figure S4). 
On average, approximately 2770 molecular formulae were identified per water sample. Of these, on average $89.8 \%$ are consistent with structures of highly unsaturated phenolics, constituting the most dominant molecular group. Compound groups of potential unsaturated aliphatics and polyphenols accounted for on average $4.9 \%$ each. Together, these three molecular groups covered $>99.5 \%$ of the total FT-ICR-MS signal intensity. DOM sampled from product-specific bottles largely reflected DOM sampled directly at the wells, yet clear differences in DOM concentration and composition between the various sources were evident (Fig. 3) and associated with distinct molecular properties (Additional file 2: Figure S10). Between-bottle variation was mostly aligned with a minor axis of compositional change (principal component 2) (Fig. 3), but was not significantly higher than instrument measurement error, i.e., the compositional variation of a routinely measured natural DOM standard (permutational test for difference in beta-diversities, minimum $p=0.51$ adjusted by Tukey HSD). For all waters and well samples, DOM consisted of many low-concentrated compounds that are usually not readily available for microbial degradation. This molecular composition with highly diluted individual DOM moieties is consistent with the high estimated age of the source waters (1.5 to 15,000 years) (Additional file 1: Table S3) [54].

\section{Discussion}

While safe supply of drinking water sustains public health, its microbiological monitoring is traditionally restricted to detecting and managing pathogenic bacteria. A more holistic understanding of drinking water microbial ecology would allow better water management, including predictive assessment of microbiological risks or benefits [55]. Research has largely focused on microorganisms that are detrimental to human health [56] or contribute to the deterioration of water distribution systems [57]. However, the natural aquatic microbiota also provides many beneficial functions for water safety, including resistance against proliferation of pathogens $[58,59]$ and degradation of contaminants [60]. Technological advances in microbial community and metabolite analysis enable a cohesive assessment of drinking water ecology. While unambiguous identification of pathogens is impossible by $16 \mathrm{~S}$ rRNA gene diversity analyses (Additional file 2) [61], nextgeneration 16S rRNA gene amplicon sequencing has revealed insights into the biogeography, assembly, and dynamics of the planktonic and biofilm communities in drinking water distribution systems [53, 62-65] and provided the basis for a first predictive framework for microbiota management [66]. In comparison, knowledge of the microbial ecology of bottled waters, another major drinking water source, is more limited. In contrast to tap water, which is usually used immediately, bottled waters may be stored for several months at ambient temperatures until consumption. Particularly in non-carbonated natural mineral waters, these storage conditions may promote a short period of rapid microbial growth early after bottling $[6,67]$.

In this study of natural mineral waters from 12 different European bottled water plants, water obtained directly from wells and freshly bottled, non-carbonated waters both contained a very low number of microbial cells ( $\leq$ $10^{4}$ cells $/ \mathrm{mL}$, Fig. 1$)$. These cells can be extremely small, are difficult to cultivate ( $\leq 100$ colony-forming units $/ \mathrm{ml}$ ), show low metabolic activity, and have low detectability by FISH (Additional file 2: Figure S1), likely due to starvation $[2,68-70]$. We show that this low-biomass, largely inactive or dormant seed microbiota has considerable diversity at various taxonomic levels in each type of bottled water. It is noteworthy that our DNA-based sequencing approach also targeted extracellular DNA (so-called "relic" DNA) [71] and thus the recovered sequences are not necessarily from living or metabolically active cells. Another, hardly avoidable problem is contaminating DNA from kits and reagents used for nucleic acid extraction and PCR or introduced during sample handling. Such contaminations specifically plague deep sequencing of environmental $16 \mathrm{~S}$ rRNA gene amplicons obtained from low-biomass samples $[25,72-74]$. Although we have removed sequences of potential contaminants (Additional file 1: Table S5) from our datasets, we cannot fully rule out the possibility that PCR amplification and sequencing of contaminating $16 \mathrm{~S}$ rRNA genes have contributed to the observed microbial diversity, particularly in the pre-growth natural mineral water samples from well waters and early after bottling.

Not surprisingly, as shown previously for two other bottled water brands [2, 4], bacterial growth and a considerable shift in microbiota composition occurred within about a week after bottling. Here, we demonstrate that only few species from the diverse, low-biomass seed microbiota became metabolically active and grew, resulting in increased similarity of the planktonic and the bottle wall-associated microbiota within and across water types. We performed FISH targeting selected bacterial groups and incorporated cell count information in bioinformatics analyses to confirm that $16 \mathrm{~S}$ rRNA gene sequences of abundant OTUs from later time points after bottling derived from actively growing bacterial populations (Additional file 2: Figure S1). Furthermore, the timing of shifts in the composition of planktonic and biofilm microbiota during the first 2 weeks after bottling (Fig. 1) indicated that bulk growth first occurred in the aquatic phase. Fewer than 15 OTUs comprised the majority of the community in each bottled water once the microbiota had reached the stationary growth phase. This pattern of community change, which included a characteristic shift from a low-diversity core microbiota of Gammaproteobacteria 
to a low-diversity core microbiota of Betaproteobacteria (mostly Comamonadaceae), is consistent with a community assembly scenario in which abiotic factors specifically select for growth of functionally and phylogenetically similar and, in this case also, ubiquitous groundwater bacteria [75]. Such environmental filtering or species sorting was recently shown to act during the assembly of microbial communities in rock pools from widespread bacterial taxa [76].

Who are the most important bacteria growing in bottled water and what are the metabolic features that support their growth? Most species that grew in the bottled waters are related to microorganisms from other oligotrophic groundwater [16] and drinking water ecosystems [53, 62-64] and were also detected in the well waters and immediately after bottling. The core OTUs that were most widespread and grew in different bottled waters (OTUs 1, 2, 225, 253, and 993) are all members of the betaproteobacterial family Comamonadaceae, including the genera Curvibacter (OTUs 1 and 253), Aquabacterium (OTUs 2 and 225), and Polaromonas (OTU 993) (Additional file 2: Figure S3). Members of these genera have been isolated from German drinking water biofilm (Aquabacterium species) [52], Japanese well water (Curvibacter fontanus) [51], and Swedish drinking water (Polaromonas aquatica) [77]. All are mesophilic chemoheterotrophs that grow under aerobic/microaerophilic conditions. Consistent with previous findings [2, 4], these genera are autochthonous microbiota members in bottled natural mineral water and are widely distributed in nutrient-poor drinking waters. OTU 2, with $100 \% 16 \mathrm{~S}$ rRNA gene identity to the biofilm-derived Aquabacterium parvum type strain (Additional file 2: Figure S3), seemed to preferentially colonize the bottle wall as it was significantly more prevalent in biofilm than in plankton samples (Fig. 5). Accessory species that grew in bottled water, i.e., non-core OTUs that were abundant after growth in one or only few water types or samples, might either be functionally redundant to the core microbiota members or metabolize substrates that are only present in certain water types or transiently present in certain water samples. Such sporadically appearing substrates may include single-carbon (C1) compounds as some members of the accessory bottled water microbiota are related to taxa (e.g., Betaproteobacteria: Methylophilaceae, Methyloversatilis in Rhodocyclaceae, Alphaproteobacteria: Methylobacteriaceae) that contain obligate and facultative methano -/methylotrophs [78]. Methano-/methylotrophic taxa are also found in drinking water distribution systems and it has been suggested that methanogenesis in anoxic sites of the source water aquifer provides methylated substrates to fuel their metabolism [53].

What are the physicochemical constraints in the different bottled waters that select for such a highly similar microbiota? Bottle material, temperature, light, and water $\mathrm{pH}$ affect the chemical composition of bottled waters during storage [79-81]. Here, all waters were stored in PET bottles at $20-24{ }^{\circ} \mathrm{C}$ in the dark, and remained well oxygenated and at a circumneutral $\mathrm{pH}$ during 1 to 2 months of storage. Total DOM concentrations varied between waters but were low $(<1.2 \mathrm{mg} / \mathrm{L})$ as in other bottled natural mineral waters [8]. These uniform habitat characteristics among all investigated waters have set the basic metabolic conditions for microbial growth in our study. In order to describe the chemical environment for growth of the bottled water microbiota in more detail, we employed ultra-high resolution mass spectrometry to characterize DOM composition in all waters and its changes during bacterial growth in two waters with maximally different DOM concentrations. Diversity of DOM, i.e., the number of identified DOM moieties, was variable between the various types of waters, and, indeed, each water had a characteristic DOM composition. Despite these differences, DOM in all waters was dominated by molecular groups that are apparently unsusceptible to immediate microbial degradation, such as highly unsaturated phenolic compounds. A unifying characteristic of the investigated waters is that they were derived from relatively old subsurface water masses that contain aged, largely refractory, humic-like DOM, similar to DOM from other subsurface aquatic environments such as karst pools [16]. The predominance of polyphenols and highly unsaturated compounds is characteristic for DOM originating from vascular plant debris and thus from terrestrial sources. Additionally, the high molecular diversity is indicative for highly processed soil-derived DOM. In contrast, fresh plant leachates, and microbially derived DOM that are typically enriched in more saturated compounds were not significant components of the bottled water DOM.

Despite lack of peptide and carbohydrate molecular formulae and the predominance of soil-derived DOM, part of the DOM could have served as substrate for the bottled water microbiota. During incubation of waters 1 and 2, specific molecular formulae indicative of polyphenolic structures decreased or increased in relative abundance (Fig. 4e, f). Relative decreases could be due to adsorption to the bottle wall or microbial degradation. Degradation of soil-derived polyphenols by the riverine microbial community was shown in a study of the Amazon River [82]. In addition, the numbers of chemically distinct molecules increased over incubation time in water 1 , suggesting an additional contribution of products of microbial metabolism to the DOM pool [83]. Despite notable differences in DOM concentration and composition, compositional change of DOM spanning the time-course experiment were similar for both waters (Figs. 4 and 5) and might be reciprocally linked to the growth of only few, related OTUs, which also 
caused the shift to similar low-diversity bacterial communities. Significant changes in DOM composition were revealed in both waters, even though water 2 had a much larger background of refractory molecules and lost a much smaller percentage of its overall DOM.

Growth of only few bacterial species was related to the significant turnover of likely hundreds of multicarbon molecules. Physiological flexibility and simultaneous utilization of multiple substrates, known as "mixed substrate growth" [9], are key adaptive features that allow microorganisms to compete and grow in oligotrophic water environments with only small concentrations of individual DOM moieties. It is tempting to speculate that individual bacterial species growing in bottled waters are substrate generalists and simultaneously forage on multiple, low-concentrated organic compounds in the diverse DOM pool. Additionally, the more refractory molecules in the DOM pool might become an increasingly important nutrient source for bacteria over prolonged storage of bottled water beyond the time frame investigated in this study. This could contribute to continuous compositional changes in the bottled water microbiota [4], maintenance of constantly high cell numbers, and only little decrease in cultivability $[5,6,67,84]$ as observed over several months after bottling.

\section{Conclusions}

This study presents the most exhaustive view to date of the microbiota in bottled natural mineral water and the interplay of its individual species with their physicochemical environment, including the highly complex DOM matrix. Despite the high molecular diversity of available DOM, the actual microbial niche space in these closed aquatic ecosystems appears rather restricted as demonstrated by the high similarity and low richness of bacteria that grew in different bottled waters. We show that turnover of hundreds of chemical molecules, from a background of $>2500$ DOM molecules, was related to the growth of less than 10 abundant species that were recruited from a seed community of up to a few hundred bacterial species. Although only a small fraction of both the chemical and microbial richness was involved, the physiologically active bacteria seemed to utilize many different and low-concentrated DOM molecules simultaneously [9]. Assembly of a characteristic low-diversity bottled water microbiota after bottling was mainly driven by abiotic factors typical for the bottled water environment. Similar shifts of DOM composition during postbottling microbial growth suggested that consumed and produced fractions of DOM are rather similar across various waters. The composition of bioavailable DOM may thus act as an important selection factor. Biotic factors, including cross-feeding on products from primary degraders of complex recalcitrant DOM molecules, may become progressively more relevant for community maintenance and dynamics during continuous storage of bottled waters over several months. We show that Curvibacter, Aquabacterium, and Polaromonas (Comamonadaceae) are habitat generalists that represent the growing core of mesophilic, heterotrophic, and aerobic bacteria in many oligotrophic natural mineral waters. Complementarily, the composition of habitat specialists, species that grew only occasionally or only in specific bottled water types, defined the "microbial uniqueness" of each bottled water. These findings are in agreement with the perception that drinking waters from different sources could be distinguished by their unique microbial and chemical composition [63]. These new insights into the microbial ecology of bottled natural mineral waters, together with the established $16 \mathrm{~S}$ rRNA gene sequence and DOM molecular datasets, are an important knowledge base and data resource for water source tracking and for developing new microbial and molecular markers for improved water quality monitoring.

\section{Additional files}

Additional file 1: Supplementary Tables. (XLSX 3393 kb)

Additional file 2: Supplementary Information. (PDF 10383 kb)

Acknowledgements

Not applicable.

Funding

This study was financed by grants from Nestec Ltd., Switzerland and the Austrian Science Fund (FWF, P25111-B22) to Alexander Loy. Cédric Gérard, Xavier Le Coz, and Sophie Gagnot from Nestec Ltd. were involved in the design of the study and in collection and physicochemical analysis of water samples.

\section{Availability of data and materials}

Sequence data supporting the conclusions of this article is available in the NCBI Sequence Read Archive (SRP091585) and GenBank (KX989480 to KX989499). The raw FT-ICR-MS dataset (as absolute peak intensities) is included within the article as Additional file 1: Table S9.

\section{Authors' contributions}

$C C L, G A S, C G$, and $A L$ designed the study. CG and $C C L$ coordinated sample collection. $C C L$ retrieved sequence data. $C C L, D B$, and $C W H$ analyzed sequence data. CCL and $C P$ performed fluorescence microscopy. CCL, CG, XLC, and SG performed physicochemical analysis. GAS, CCL, TD, and JN performed ultra-high mass spectrometry analysis; GAS, DB, and CWH performed statistical analysis. AL wrote the paper with contributions from $\mathrm{CCL}, \mathrm{CWH}$, and GAS. All authors revised and approved the manuscript.

Ethics approval and consent to participate Not applicable.

Consent for publication

Not applicable.

\section{Competing interests}

The study was financed by Nestec Ltd., Switzerland. Co-authors Cédric Gérard, Xavier Le Coz, and Sophie Gagnot are employees of Nestec Ltd. 


\section{Publisher's Note}

Springer Nature remains neutral with regard to jurisdictional claims in published maps and institutional affiliations.

\begin{abstract}
Author details
'Department of Microbiology and Ecosystem Science, Division of Microbial Ecology, Research Network Chemistry meets Microbiology, University of Vienna, Althanstrasse 14, A-1090 Vienna, Austria. ${ }^{2}$ Department of Ecohydrology, Leibniz-Institute of Freshwater Ecology and Inland Fisheries, Müggelseedamm 310, D-12587 Berlin, Germany. ${ }^{3}$ University of Oldenburg, Institute for Chemistry and Biology of the Marine Environment, ICBM-MPI Bridging Group for Marine Geochemistry, Carl-von-Ossietzky-Straße 9-11, D-26129 Oldenburg, Germany. ${ }^{4}$ Nestec Ltd., Route du Jorat 57, CH-1000 Lausanne 26, Switzerland.
\end{abstract}

Received: 17 March 2017 Accepted: 15 September 2017

Published online: 22 September 2017

\section{References}

1. Buttiaux R, Boudier A. Comportement des bactéries autotrophes dans les eaux minérales conservées en récipients hermétiquement clos. Annales de I'Institut Pasteur de Lille. 1960;11:43-52.

2. Loy $A$, Beisker $W$, Meier $H$. Diversity of bacteria growing in natural mineral water after bottling. Appl Environ Microbiol. 2005;71:3624-32.

3. Leclerc H, Da Costa MS. Microbiology of natural mineral waters. In: Senior DAG, Ashurst PR, editors. Technology of bottled water. Sheffield: Sheffield Academic Press Ltd; 1998. p. 223-73.

4. Franca L, Lopez-Lopez A, Rossello-Mora R, da Costa MS. Microbial diversity and dynamics of a groundwater and a still bottled natural mineral water. Environ Microbiol. 2015;17:577-93.

5. Morais PV, da Costa MS. Alterations in the major heterotrophic bacterial populations isolated from a still bottled mineral water. J Appl Bacteriol. 1990;69:750-7

6. Vachée A, Vincent $P$, Struijk CB, Mossel DAA, Leclerc $H$. A study of the fate of the autochtonous bacterial flora of still mineral waters by analysis of restriction fragment length polymorphism of genes coding for rRNA. Syst Appl Microbiol. 1997;20:492-503.

7. Casanovas-Massana A, Blanch AR. Diversity of the heterotrophic microbial populations for distinguishing natural mineral waters. Int J Food Microbiol. 2012;153:38-44.

8. Leclerc $H$, Moreau A. Microbiological safety of natural mineral water. FEMS Microbiol Rev. 2002:26:207-22.

9. Egli T. How to live at very low substrate concentration. Water Res. 2010:44:4826-37.

10. Raymond PA, Bauer JE. Riverine export of aged terrestrial organic matter to the North Atlantic Ocean. Nature. 2001:409:497-500.

11. Singer GA, Fasching C, Wilhelm L, Niggemann J, Steier P, Dittmar T, Battin TJ. Biogeochemically diverse organic matter in alpine glaciers and its downstream fate. Nat Geosci. 2012;5:710-4.

12. Arrieta JM, Mayol E, Hansman RL, Herndl GJ, Dittmar T, Duarte CM. Dilution limits dissolved organic carbon utilization in the deep ocean. Science. 2015;348:331-3.

13. Dittmar T. The molecular level determination of black carbon in marine dissolved organic matter. Org Geochem. 2008;39:396-407.

14. Osterholz H, Singer G, Wemheuer B, Daniel R, Simon M, Niggemann J, Dittmar $T$. Deciphering associations between dissolved organic molecules and bacterial communities in a pelagic marine system. ISME J. 2016;10:1717-30.

15. Kellerman AM, Dittmar T, Kothawala DN, Tranvik L. Chemodiversity of dissolved organic matter in lakes driven by climate and hydrology. Nat Commun. 2014;5:3804

16. Shabarova T, Villiger J, Morenkov O, Niggemann J, Dittmar T, Pernthaler J. Bacterial community structure and dissolved organic matter in repeatedly flooded subsurface karst water pools. FEMS Microbiol Ecol. 2014:89:111-26.

17. Longnecker K, Da Costa A, Bhatia M, Kujawinski EB. Effect of carbon addition and predation on acetate-assimilating bacterial cells in groundwater. FEMS Microbiol Ecol. 2009:70:456-70

18. Daims H, Lücker S, Wagner M. Daime, a novel image analysis program for microbial ecology and biofilm research. Environ Microbiol. 2006:8:200-13.

19. Greuter D, Loy A, Horn M, Rattei T. probeBase-an online resource for rRNA targeted oligonucleotide probes and primers: new features 2016. Nucleic Acids Res. 2016:44:D586-9.
20. Pruesse E, Quast C, Knittel K, Fuchs BM, Ludwig W, Peplies J, Glockner FO. SILVA: a comprehensive online resource for quality checked and aligned ribosomal RNA sequence data compatible with ARB. Nucleic Acids Res. 2007:35:7188-96.

21. Ludwig W, Strunk O, Westram R, Richter L, Meier H, Yadhukumar, Buchner A Lai T, Steppi S, Jobb G, et al. ARB: a software environment for sequence data. Nucleic Acids Res. 2004;32:1363-71.

22. Loy A, Arnold R, Tischler P, Rattei T, Wagner M, Horn M. probeCheck-a central resource for evaluating oligonucleotide probe coverage and specificity. Environ Microbiol. 2008;10:2894-6.

23. Cole JR, Wang Q, Fish JA, Chai B, McGarrell DM, Sun Y, Brown CT, Porras-Alfaro A, Kuske CR, Tiedje JM. Ribosomal database project: data and tools for high throughput rRNA analysis. Nucleic Acids Res. 2014;42:D633-42

24. Berry D, Ben Mahfoudh K, Wagner M, Loy A. Barcoded primers used in multiplex amplicon pyrosequencing bias amplification. Appl Environ Microbiol. 2011:77:7846-9.

25. Salter SJ, Cox MJ, Turek EM, Calus ST, Cookson WO, Moffatt MF, Turner P, Parkhill J, Loman NJ, Walker AW. Reagent and laboratory contamination can critically impact sequence-based microbiome analyses. BMC Biol. 2014;12:87.

26. Quince C, Lanzen A, Davenport RJ, Turnbaugh PJ. Removing noise from pyrosequenced amplicons. BMC Bioinformatics. 2011;12:38.

27. Caporaso JG, Kuczynski J, Stombaugh J, Bittinger K, Bushman FD, Costello EK, Fierer N, Pena AG, Goodrich JK, Gordon Jl, et al. QIIME allows analysis of high-throughput community sequencing data. Nat Methods. 2010;7:335-6.

28. Berry D, Schwab C, Milinovich G, Reichert J, Ben Mahfoudh K, Decker T, Engel M, Hai B, Hainzl E, Heider S, et al. Phylotype-level 16S rRNA analysis reveals new bacterial indicators of health state in acute murine colitis. ISME journal. 2012;6:2091-106

29. Edgar RC. UPARSE: highly accurate OTU sequences from microbial amplicon reads. Nat Methods. 2013;10:996-8.

30. Wang Q, Garrity GM, Tiedje JM, Cole JR. Naive Bayesian classifier for rapid assignment of rRNA sequences into the new bacterial taxonomy. Appl Environ Microbiol. 2007:73:5261-77.

31. Quast C, Pruesse E, Yilmaz P, Gerken J, Schweer T, Yarza P, Peplies J, Glockner FO. The SILVA ribosomal RNA gene database project: improved data processing and web-based tools. Nucleic Acids Res. 2013;41:D590-6.

32. Team RC. R: a language and environment for statistical computing. Vienna: R Foundation for Statistical Computing; 2015.

33. Oksanen J, Blanchet FG, Kindt R, Legendre P, Minchin PR, O'Hara RB, Simpson GL, Solymos P, Stevens MHH, Wagner H. Vegan: community ecology package, vol. 2.3-5; 2016. https://cran.r-project.org/, https://github. com/vegandevs/vegan

34. McMurdie PJ, Holmes S. Phyloseq: an R package for reproducible interactive analysis and graphics of microbiome census data. PLoS One. 2013;8:e61217.

35. Katoh K, Standley DM. MAFFT multiple sequence alignment software version 7 : improvements in performance and usability. Mol Biol Evol. 2013;30:772-80.

36. Loy A, Lehner A, Lee N, Adamczyk J, Meier H, Ernst J, Schleifer K-H, Wagner M. Oligonucleotide microarray for $16 \mathrm{~S}$ rRNA gene-based detection of all recognized lineages of sulfate-reducing prokaryotes in the environment. Appl Environ Microbiol. 2002;68:5064-81.

37. Yarza P, Ludwig W, Euzeby J, Amann R, Schleifer KH, Glockner FO, RosselloMora R. Update of the all-species living tree project based on 165 and 235 rRNA sequence analyses. Syst Appl Microbiol. 2010;33:291-9.

38. Pruesse E, Peplies J, Glockner FO. SINA: accurate high-throughput multiple sequence alignment of ribosomal RNA genes. Bioinformatics. 2012;28:1823-9.

39. Stamatakis A. RAxML version 8: a tool for phylogenetic analysis and postanalysis of large phylogenies. Bioinformatics. 2014;30:1312-3.

40. Lartillot N, Lepage T, Blanquart S. PhyloBayes 3: a Bayesian software package for phylogenetic reconstruction and molecular dating. Bioinformatics. 2009;25:2286-8.

41. Vital M, Fuchslin HP, Hammes F, Egli T. Growth of Vibrio cholerae 01 Ogawa Eltor in freshwater. Microbiol. 2007;153:1993-2001.

42. Dittmar T, Koch B, Hertkorn N, Kattner G. A simple and efficient method for the solid-phase extraction of dissolved organic matter (SPE-DOM) from seawater. Limnol Oceanogr-Meth. 2008:6:230-5.

43. Koch BP, Dittmar T, Witt M, Kattner G. Fundamentals of molecular formula assignment to ultrahigh resolution mass data of natural organic matter. Anal Chem. 2007;79:1758-63.

44. Payne TG, Southam AD, Arvanitis TN, Viant MR. A signal filtering method for improved quantification and noise discrimination in fourier transform ion 
cyclotron resonance mass spectrometry-based metabolomics data. J Am Soc Mass Spectrom. 2009;20:1087-95.

45. Koch BP, Dittmar T. From mass to structure: an aromaticity index for highresolution mass data of natural organic matter (vol 20, pg 926, 2006). Rapid Commun Mass Sp. 2016;30:250.

46. Legendre P, Legendre L. Numerical Ecology. 2nd ed. Amsterdam: Elsevier Science B.V; 1998.

47. Venables WN, Ripley BD. Modern applied statistics with S, fourth edition edn. New York: Springer; 2002.

48. Stolper DA, Revsbech NP, Canfield DE. Aerobic growth at nanomolar oxygen concentrations. Proc Natl Acad Sci U S A. 2010;107:18755-60.

49. Wilhartitz I, Mach RL, Teira E, Reinthaler T, Herndl GJ, Farnleitner AH. Prokaryotic community analysis with CARD-FISH in comparison with FISH in ultraoligotrophic ground- and drinking water. J Appl Microbiol. 2007;103:871-81.

50. Brown CT, Hug LA, Thomas BC, Sharon I, Castelle CJ, Singh A, Wilkins MJ, Wrighton KC, Williams KH, Banfield JF. Unusual biology across a group comprising more than 15\% of domain bacteria. Nature. 2015;523:208-11.

51. Ding LX, Yokota A. Curvibacter fontana sp nov., a microaerobic bacteria isolated from well water. J Gen Appl Microbiol. 2010;56:267-71.

52. Kalmbach S, Manz W, Wecke J, Szewzyk U. Aquabacterium gen. nov., with description of Aquabacterium citratiphilum sp. nov., Aquabacterium parvum sp. nov. and Aquabacterium commune sp. nov., three in situ dominant bacterial species from the Berlin drinking water system. Int J Syst Bacteriol. 1999;49:769-77.

53. Ling F, Hwang C, LeChevallier MW, Andersen GL, Liu WT. Core-satellite populations and seasonality of water meter biofilms in a metropolitan drinking water distribution system. ISME J. 2016;10:582-95.

54. Dittmar T. Reasons behind the long-term stability of dissolved organic matter, Biogeochemistry of marine dissolved organic matter. 2nd ed; 2015. p. 369-88.

55. Berry D, Xi C, Raskin L. Microbial ecology of drinking water distribution systems. Curr Opin Biotechnol. 2006;17:297-302.

56. Egli T, Koster W, Meile L. Pathogenic microbes in water and food: changes and challenges. FEMS Microbiol Rev. 2002;26:111-2.

57. Coetser SE, Cloete TE. Biofouling and biocorrosion in industrial water systems. Crit Rev Microbiol. 2005;31:213-32.

58. Moreira L, Agostinho P, Morais PV, da Costa MS. Survival of allochthonous bacteria in still mineral water bottled in polyvinyl chloride (PVC) and glass. J Appl Bacteriol. 1994;77:334-9.

59. Vital M, Hammes F, Egli T. Competition of Escherichia coli $\mathrm{O} 157$ with a drinking water bacterial community at low nutrient concentrations. Water Res. 2012;46:6279-90.

60. Mutsuga M, Kawamura Y, Sugita-Konishi Y, Hara-Kudo Y, Takatori K, Tanamoto K. Migration of formaldehyde and acetaldehyde into mineral water in polyethylene terephthalate (PET) bottles. Food Addit Contam. 2006;23:212-8.

61. Ceuppens S, Li D, Uyttendaele M, Renault P, Ross P, Van Ranst M, Cocolin L, Donaghy J. Molecular methods in food safety microbiology: interpretation and implications of nucleic acid detection. Compr Rev Food Sci F. 2014;13: 551-77.

62. Pinto AJ, Xi C, Raskin L. Bacterial community structure in the drinking water microbiome is governed by filtration processes. Environ Sci Technol. 2012; 46:8851-9.

63. Roeselers G, Coolen J, van der Wielen PW, Jaspers MC, Atsma A, de Graaf B, Schuren F. Microbial biogeography of drinking water: patterns in phylogenetic diversity across space and time. Environ Microbiol. 2015;17:2505-14.

64. Liu G, Bakker GL, Li S, Vreeburg JH, Verberk JQ, Medema GJ, Liu WT, Van Dijk JC. Pyrosequencing reveals bacterial communities in unchlorinated drinking water distribution system: an integral study of bulk water, suspended solids, loose deposits, and pipe wall biofilm. Environ Sci Technol. 2014;48:5467-76.

65. Ren H, Wang W, Liu Y, Liu S, Lou L, Cheng D, He X, Zhou X, Qiu S, Fu L, et al. Pyrosequencing analysis of bacterial communities in biofilms from different pipe materials in a city drinking water distribution system of East China. Appl Microbiol Biotechnol. 2015;99:10713-24.

66. Pinto AJ, Schroeder J, Lunn M, Sloan W, Raskin L. Spatial-temporal survey and occupancy-abundance modeling to predict bacterial community dynamics in the drinking water microbiome. MBio. 2014;5:e01135-14.

67. Bischofberger T, Cha SK, Schmitt R, Konig B, Schmidt-Lorenz W. The bacterial flora of non-carbonated, natural mineral water from the springs to reservoir and glass and plastic bottles. Int J Food Microbiol. 1990;11:51-71.

68. Ferreira AC, Morais PV, da Costa MS. Alterations in total bacteria, iodonitrophenyltetrazolium (INT)-positive bacteria, and heterotrophic plate counts of bottled mineral water. Can J Microbiol. 1993;40:72-7.
69. Jones $C R$, Chamberlain $A H$, Adams MR. An investigation of the presence of ultramicrocells in natural mineral water. Lett Appl Microbiol. 1999;28:275-9.

70. Luef B, Frischkorn KR, Wrighton KC, Holman HY, Birarda G, Thomas BC, Singh A, Williams KH, Siegerist CE, Tringe SG, et al. Diverse uncultivated ultra-small bacterial cells in groundwater. Nat Commun. 2015;6:6372.

71. Carini P, Marsden PJ, Leff JW, Morgan EE, Strickland MS, Fierer N. Relic DNA is abundant in soil and obscures estimates of soil microbial diversity. Nat Microbiol. 2016;2:16242.

72. Laurence M, Hatzis C, Brash DE. Common contaminants in next-generation sequencing that hinder discovery of low-abundance microbes. PLoS One. 2014;9:e97876.

73. Herbold CW, Pelikan C, Kuzyk O, Hausmann B, Angel R, Berry D, Loy A. A flexible and economical barcoding approach for highly multiplexed amplicon sequencing of diverse target genes. Front Microbiol. 2015;6:731.

74. Biesbroek G, Sanders EA, Roeselers G, Wang X, Caspers MP, Trzcinski K, Bogaert D, Keijser BJ. Deep sequencing analyses of low density microbial communities: working at the boundary of accurate microbiota detection. PLoS One. 2012;7:e32942.

75. Langenheder $\mathrm{S}$, Ragnarsson $\mathrm{H}$. The role of environmental and spatial factors for the composition of aquatic bacterial communities. Ecology. 2007;88:2154-61.

76. Szekely AJ, Langenheder S. The importance of species sorting differs between habitat generalists and specialists in bacterial communities. FEMS Microbiol Ecol. 2014;87:102-12.

77. Kämpfer P, Busse HJ, Falsen E. Polaromonas aquatica sp. nov., isolated from tap water. Int J Syst Evol Microbiol. 2006:56:605-8.

78. Chistoserdova L, Kalyuzhnaya MG, Lidstrom ME. The expanding world of methylotrophic metabolism. Annu Rev Microbiol. 2009;63:477-99.

79. Baumjohann N, Harms D. Development of an LC-MS/MS method for studying migration characteristics of acetaldehyde in polyethylene terephthalate (PET)-packed mineral water. Food Addit Contam A. 2015;32: 1552-60.

80. Reimann C, Birke M, Filzmoser P. Bottled drinking water: water contamination from bottle materials (glass, hard PET, soft PET), the influence of colour and acidification. Appl Geochem. 2010;25:1030-46.

81. Abboudi M, Odeh A. Impact of sunlight/dark storage on natural spring water bottled in polyethylene terephthalate. J Water Supply Res T. 2015;64:149-56

82. Ward ND, Keil RG, Medeiros PM, Brito DC, Cunha AC, Dittmar T, Yager PL, Krusche AV, Richey JE. Degradation of terrestrially derived macromolecules in the Amazon River. Nat Geosci. 2013;6:530-3.

83. Osterholz H, Niggemann J, Giebel HA, Simon M, Dittmar T. Inefficient microbial production of refractory dissolved organic matter in the ocean. Nat Commun. 2015;6:7422

84. Gonzalez C, Gutierrez C, Grande T. Bacterial flora in bottled uncarbonated mineral drinking water. Can J Microbiol. 1987;33:1120-5.

\section{Submit your next manuscript to BioMed Central and we will help you at every step:}

- We accept pre-submission inquiries

- Our selector tool helps you to find the most relevant journal

- We provide round the clock customer support

- Convenient online submission

- Thorough peer review

- Inclusion in PubMed and all major indexing services

- Maximum visibility for your research

Submit your manuscript at www.biomedcentral.com/submit
Biomed Central 